\title{
Experimental Study on Assembled Monolithic Concrete Shear Walls Built with Precast Two-Way Hollow Slabs
}

\author{
Zhijuan Sun ${ }^{1}$, Yukun $\mathrm{Mao}^{2}$, Jiliang $\mathrm{Liu}^{3}$, Qinyan Zhao ${ }^{3}$ and Mingjin $\mathrm{Chu}^{3}{ }^{3 *}$ \\ ${ }^{1}$ School of Architecture, Yantai University, Yantai, 264005, China \\ ${ }^{2}$ Zhongjiao Tongli Construction Co., Ltd., Xi'an 710075, China \\ ${ }^{3}$ School of Civil Engineering, Yantai University, Yantai, 264005, China
}

\begin{abstract}
Assembled shear wall built with precast two-way hollow slab is a new-typed shear wall built with precast concrete. In order to study its mechanical property, a quasi-static experiment is conducted with 1 reinforced concrete shear wall and 2 new type shear walls as the study objects. It was found that the internal and vertical joints of the wall body were vulnerable parts so that the new-typed shear wall experienced the loading process from the whole wall to the portioned wall. So, brittle shear failure can be avoided, deformability and anti-collapse performance are greatly improved, and shear capacity of wall body is reduced. The new-typed shear wall is reasonably structured, with convenient and reliable horizontal and vertical reinforcement, which leads to satisfactory vertical joint force-bearing capacity. Thus, it can be applied in practical construction.
\end{abstract}

Keywords: Design method, joints, mechanical behavior, practical construction, precast concrete structure, shear walls,.

\section{INTRODUCTION}

Precast concrete structure, including precast frame structure, shear wall structure, and frame-shear wall structure, has lots of advantages, such as protecting environment, saving resource and saving energy, etc. Shear wall structure is of high rigidity and bearing capacity, and it also has better anti-seismic property than frame structure [1]. In several past strong earthquakes, such as Mexican earthquake (1985), Armenian earthquake (1988) and Kobe earthquake (1995), precast concrete shear wall structure presented good performance [1], [3]. As for this, it is a good choice for earthquake regions to adopt precast concrete shear wall structure.

The key to precast concrete structure is joint technology. In order to improve the installation convenience and reliability of horizontal and vertical reinforcement, as well as to enhance the overall stability of structure, an assembled shear wall structure built with precast two-way hollow slab is designed in this paper. Basic assembly unit of the structure is precast two-way hollow slab, with vertical and horizontal holes to form cross channels (see Fig. (1)). In practical construction, precast two-way hollow slabs are used as templates to form spatial skeleton. Horizontal reinforcements are inserted into horizontal channels, while vertical reinforcements are inserted into vertical channels. On this basis, concrete is grouted to form an integral structure.

*Address correspondence to this author at the School of Civil Engineering, Yantai University, Yantai, 264005, China; Tel: +86 535 6902606;

Fax: +86 535 6902606; E-mail: housind@163.com

\section{RESEARCH ON ANTI-SEISMIC PROPERTY OF PRECAST CONCRETE SHEAR WALL}

Researches on precast concrete shear wall structure mainly involve joint connection performance, and shear wall anti-seismic property, etc.

\section{Research on Performance of Joint Connection}

Precast concrete structure is assembled into integrity by nodes and joints. In precast concrete shear wall structure, the mechanical property of horizontal joints and vertical joints determines the overall performance of the structure, as well as corresponding design scheme and construction technique. The mechanical property of joints in precast concrete shear wall structure relies on the performance of concrete junction face, especially the bearing capacity of reinforcement crossing the junction face. The performance of concrete junction face is mainly determined by the shearing capacity of the interface between new and old concrete. According to

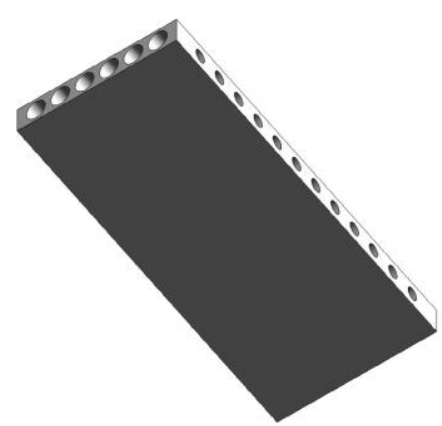

Fig. (1). Precast two-way hollow slab. 
some former related researches, factors influencing new-old concrete interface include strength of new and old concrete body, roughness of the interface, as well as location of the interface. Normally, strength of the interface is weaker than the strength of both new and old concrete body. Within a certain range, higher roughness leads to stronger shearing capacity [4][5]. Reinforcement passing the junction face are designed to improve the ductility of the interface. Within a certain range, higher bearing capacity of reinforcement leads to better shearing capacity [6]. Joints of precast concrete shear wall structure are usually reserved with key slots. Some researches revealed the influence of key slot size, quantity, shape and shear reinforcement ratio on sharing capacity of the junction face, with calculation formula proposed [7].

In assembled shear wall structure built with precast twoway hollow slab, vertical joints include post-grouted concrete at horizontal channels, horizontal reinforcement, as well as the junction face between new and old concrete. Similarly, horizontal joints include post-grouted concrete at vertical channels, vertical reinforcement, as well as the junction face between new and old concrete. Horizontal reinforcement and vertical reinforcement extend continuously in the channels, free from casing grouting anchor connection, casing grouting connection or other connection techniques. So joint formation of the new-typed shear wall structure is different from existing structures [811]. In addition, the junction part between post-grouted concrete in channels of precast two-way slab and precast concrete is also a weak link of the structure, which needs to be further studied.

\section{Research on Anti-seismic Property of Precast Concrete Shear Wall Structure}

Shear slip of shear wall along horizontal joints is adverse to anti-seismic property of the structure [12]. Thus, horizontal joints of precast concrete shear wall structure shall be processed to avoid shear slipping, similar to the effect of cast-in-situ [13]. Reinforcement for horizontal joints in existing precast concrete shear wall structure is usually connected with casing grouting anchor or casing grouting [14],[15].

Performance requirement on vertical joints of precast concrete shear wall is involved with two academic points: one requires high joint strength to achieve similar performance with cast-in-place shear wall. The other one requires relatively lower strength, so as to improve the energy dissipation ability of shear wall. In China, precast concrete shear wall structure is often expected to be similar to cast-in-place shear wall structure [15][16].

\section{EXPERIMENTAL RESEARCH}

In order to study the mechanical performance of the newtyped shear wall, as well as to figure out joint's influence on wall body, quasi-static test was performed on 3 shear walls: RC shear wall SW0, the new-typed shear wall SW1 and DW1. SW1 consisted a precast two-way hollow slab, with no vertical joint. DW1 has vertical joint with the width of $20 \mathrm{~mm}$. The sectional size of the wall body is $180 \mathrm{~mm}$ $\times 1440 \mathrm{~mm}$, depth-width ratio is 1.5 , and experiment axial compression ratio is 0.15 . The profiles of SW1 and DW1 are shown in Fig. (2), where, section along horizontal channel and the dash area are precast concrete, while the rest are post-cast concrete.

Fig. (3) shows the peak load and breakdown point. Breakdown point is where bearing capacity decreases to $85 \%$ of the peak load. Vertex horizontal force-displacement hysteresis curve is shown in Fig. (4).

According to the test, the width of diagonal crack of SW0 at peak load increases sharply, while the horizontal bearing capacity and vertical bearing capacity decreases rapidly,

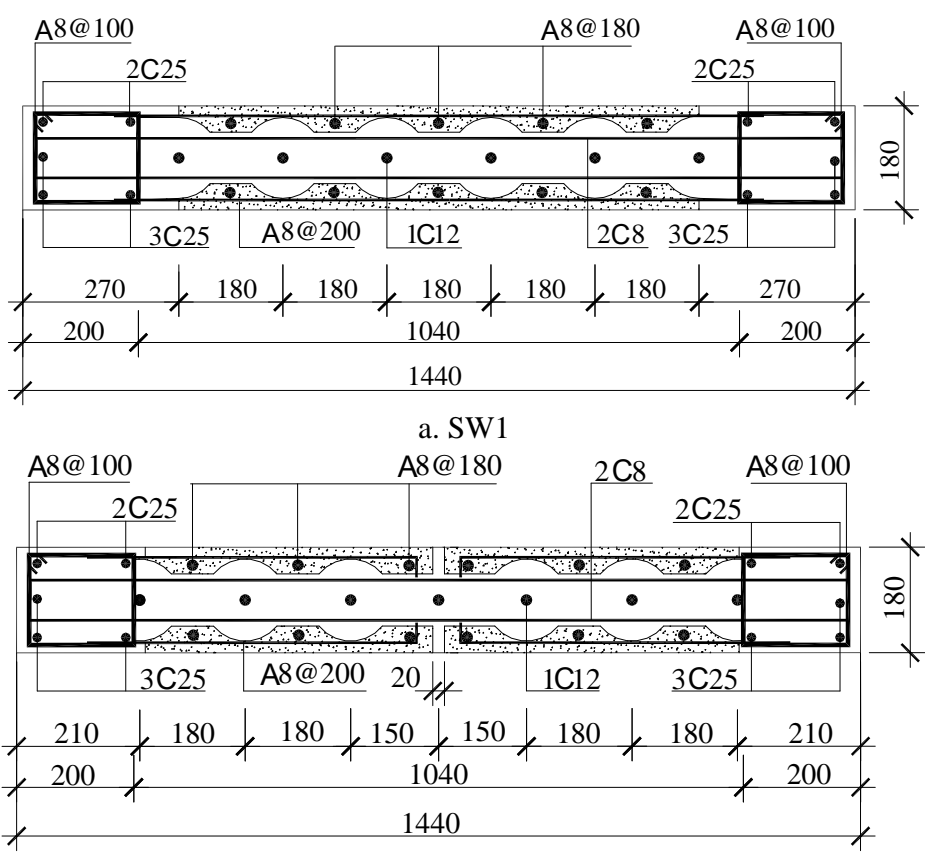

b. DW1

Fig. (2). Profile of test specimen. 
leading to brittle shear failure. Photos when the wall is under Peak load and breakdown point are shown in Fig. (3a) and Fig. (3b).

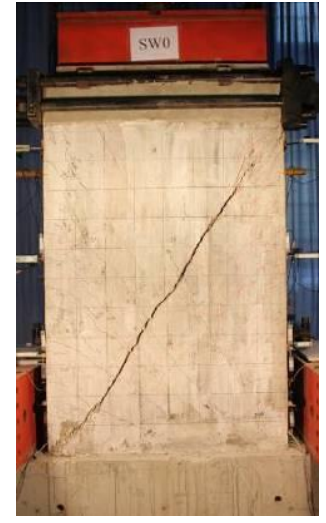

A. Failure at peak load point (Bearing capacity $965 \mathrm{kn}$, displacement angle 1/138.2)

\section{SW0 - Traditional shear wall}

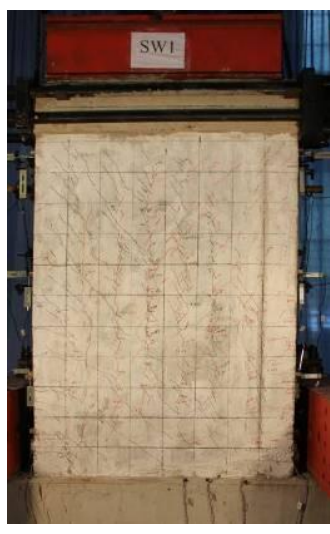

C. Failure at peak load point (Bearing capacity $870 \mathrm{kn}$, displacement angle 1/144)

SW1 - The new-typed shear wall

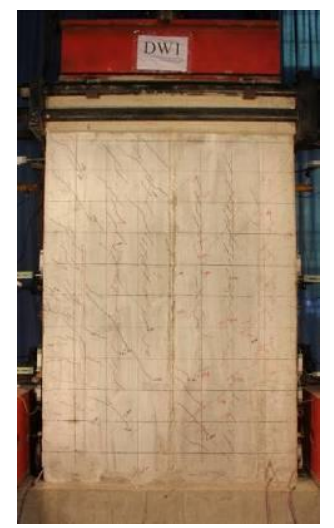

E. Peak Load Point Bearing Capacity 778 kN, Displacement Angle 1/137.8)

DW1 - The new-typed shear wall with vertical joint

Fig. (3). Destruction process of test specimen
Destruction process of the new-typed shear wall is comprised by two phases: the whole wall and the portioned wall stages. The destruction process of SW1 is shown as follows:

\section{Monolithic Wall Loading Phase}

In the initial loading phase, the skeleton curve of SW1 is basically identical with SW0. With the lateral load increases, SW1 is found with plenty of vertical macro-cracks comprised by short and thin cracks in vertical channels (i.e. internal joints) along the precast two-way hollow slab (see Fig. (3c)). Before peak load appears, the influence of vertical cracks on wall body is quite limited, and the monolithic wall is carrying the load as a whole. Vertical joints avoid the development of oblique cracks so that it can prevent the cracks from becoming diagonal cracks, avoiding brittle failure.

\section{Partitioned Wall Loading Phase}

At peak load, the relative deformation on both sides of the vertical macro-cracks of SW1 increases suddenly (see Fig. (3c)). Horizontal reinforcement yielded, and the ultimate bearing capacity is decreased $20 \%$ than SW0. After the peak load, concrete around vertical cracks is gradually damaged. The failure of SW1 is transformed from a whole wall into several portioned wall, so its deformability is improved. Damage and destruction of SW1 are mainly distributed around vertical cracks. By contrast, wall columns and boundary components are basically intact (refer to Fig. (3d)). Vertical bearing capacity decreases a little.

The destruction process of DW1 also experiences two similar phases. The only difference is that relatively deformation appears along vertical joints before DW1 reaches peak load. Therefore, the wall enters partitioned wall loading phase. There are internal cracks in wall bodies on both sides of the vertical joints of DW1. As for this, under the effect of lateral load, vertical macro-cracks appear. When relative deformation on both sides of the vertical cracks suddenly increases to the peak load (see Fig. (3e)), deformation at vertical joints increase the practical shear span ratio of the wall body, with its ultimate bearing capacity $16 \%$ lower than SW1. However, the deformability is greatly improved. After the peak load, vertical cracks and vertical joints divide the wall body into sub-walls comprised by walls and columns (see Fig. (3f)).

\section{MECHANICAL PROPERTY}

According to the experimental researches, internal joints change the destruction form and mode of the new-typed shear wall. As a result, the destruction process of wall body experiences two phases: from the whole wall to the portioned wall, the brittle failure can be avoided, the ductility and energy-dissipating capacity are improved. Damage and destruction area of wall body concentrate in vertical crack area, leading to higher vertical bearing capacity to avoid structure collapse.

According to the test result, the new-typed shear wall with vertical joints was found with relative deformation along vertical joints before the peak load is reached. Then, 


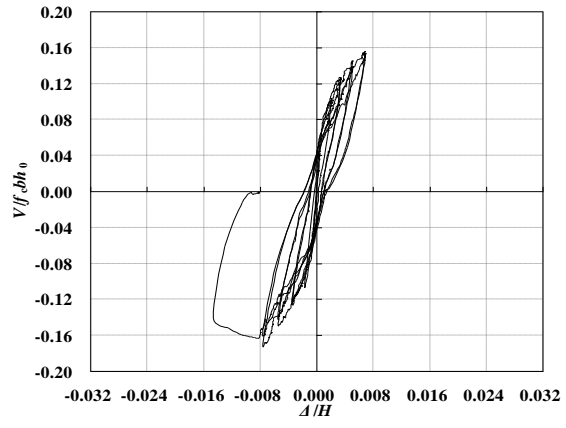

SW0

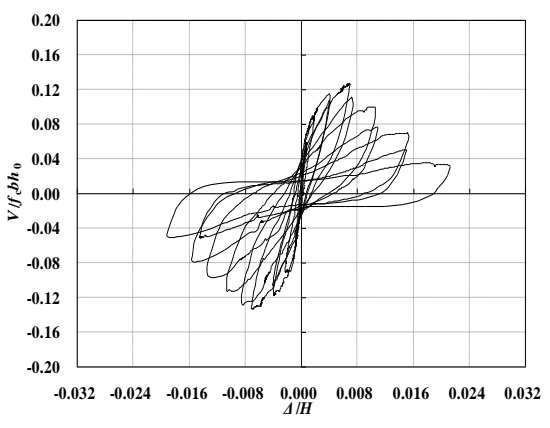

SW1

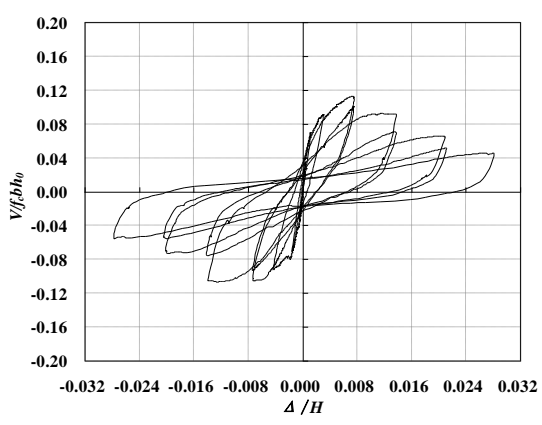

DW1

Fig. (4).Vertex horizontal force - displacement hysteresis curve.

the wall body is developed into portioned wall, which made the practical shear span ratio and deformability of wall body be improved. There are internal joints in wall body on both sides of vertical joints. Vertical macro-cracks appear under lateral load, avoiding shear failure. At peak load, relative deformation is found on both sides of vertical macro-cracks. Then the wall body evolves into partitioned wall comprised by several wall columns, deformability can be improved further.

Internal joints and vertical joints endow the new-typed shear wall with self-adaption partition performance. Under lateral load, vertical cracks appear along internal joints and vertical joints in wall body. The appearance and form of vertical crack is in line with the lateral load born by wall body. If the lateral load is small, there shall be no vertical crack in wall body, and the whole wall is under stress. When the lateral load increases, vertical cracks develop obviously, so that the wall body evolves into portioned wall loading phase.

The performance of traditional shear wall under small scale earthquake can be guaranteed. Under large scale earthquakes, brittle shear failure can occur [17]. Even if there is bending failure, wall body damage normally concentrates in button plastic hinge area. At the mean time of dissipating energy, bearing capacity loss is often quite considerable, so that the performance of the whole wall body is difficult to be ensured [18]. The new-typed shear wall can prevent brittle failure. Damage and energy dissipation are distributed in vertical cracks and vertical joint area. The area is large and dispersive, avoiding concentrated energy dissipation at the bottom. Hereby, the bearing capacity of the structure can be guaranteed, so anti-collapse ability is improved.

\section{CONCLUSION}

The key to precast concrete shear wall structure is joint technology. Basic assembly unit of the structure is precast two-way hollow slab, with vertical and horizontal holes to form cross channels, for the convenience of horizontal reinforcement and vertical reinforcement connection. Quasistatic test on 3 wall bodies is described in the paper, with the objective to study the mechanical performance of the newtyped wall body. Test results show the new-typed shear wall has reasonable structure, while horizontal reinforcement and vertical reinforcement connection are convenient and reliable. In elastic phase, the mechanical property of the new-typed shear wall is basically the same with reinforcement concrete shear wall. Internal joints and vertical joints are important factors to affect the performance of wall body, dividing the destruction process of the newtyped shear wall into two phases: the whole wall phase and the portioned wall phase. Brittle shear failure can be avoided, the ductility and energy dissipation ability are improved, while the anti-collapse performance are enhanced.

\section{CONFLICT OF INTEREST}

The authors confirm that this article content has no conflicts of interest.

\section{ACKNOWLEDGEMENTS}

The authors are grateful to the support of National Science Foundation of China (Grant No. 51378450) and the Project of Shandong Province Higher Educational Science and Technology Program (Grant No. J13LG09).

\section{REFERENCES}

[1] M. Fintel, "Ductile shear walls in earthquake resistant multistory buildings," ACIJ, vol. 71, no. 9, pp. 296-305, 1974.

[2] M. Fintel, "Performance of buildings with shear walls in earthquakes of the last thirty years," PCIJ, vol. 40, no. 3, pp. 62-80, 1995.

[3] H. Muguruma, M. Nishiyarna, and F. Watanabe, "Lessons learned from the Kobe earthquake - a Japanese perspective," PCIJ, vol.40, no.4, pp. 28-42, 1995.

[4] E. N. Julio, F. A. B. Branco and V. D. Silva, "Concrete-to-concrete bond strength. Influence of the roughness of the substrate surface," Construct. Build. Mat., vol. 18, no. 9, pp. 675-681, 2004.

[5] L.S. Castillo, and A.A. deCea, "Bi-layer diaphragm walls: Evolution of concrete-to- concrete bond strength at early ages," Construct. Build. Mat., vol. 31, no. 1, pp. 29-37, 2012.

[6] M. Gohnert, "Horizontal shear transfer across a roughened surface," Cement. Concrete Composit., vol. 25, no. 3, pp. 379-385, 2003.

[7] S.G. Tsoukantas, and T.P. Tassios, "Shear resistance of connections between reinforced concrete linear precast element," ACI Struct. J., vol. 86, no. 3, pp. 242-249, 1989.

[8] G. Song, D. Huo, D. Wang, and B. Liu, "Shear capacity of verticalgrooved connection in PBP structures," China Civil Eng. J., vol. 33, no. 11, pp. 61-64, 2003. 
[9] Z. Fin, Y. Zhu, and S. Yang, et al, "Earthquake simulation tests of tall buildings with precast large panel", China Civil Eng. J., vol. 29, no. 3, pp. 57-64, 1996.

[10] Y. Peng, "Experimental Study on Seismic Behavior of Pre-cast Reinforced Concrete Shear Walls," D.S. thesis, Tsinghua University, Beijing, China, 2010.

[11] Q. Jiang, X. Ye, and X. Chong, "Calculation model for superimposed slab shear walls," China Civil Eng. J., vol. 45, no. 1, pp. 8-12, 2012.

[12] T. N. Salonikios, A. J. Kappos, I. A. Tegos, and G.G. Penelis, "Cyclic load behavior of low-slenderness reinforced concrete walls-failure modes, strength and deformation analysis, and design implications," ACI Struct. J., vol. 97, no. 1, pp. 132-142, 2000.

[13] D. Wang, and X. Lu, "Progress of study on seismic performance of precast concrete shear wall systems," Struct. Eng., vol. 26, no. 6, pp. 128-135, 2010.
[14] Z. Zhu, and Z. Guo, "Seismic test and analysis of joints of new precast concrete shear wall structures," China Civil Eng. J., vol. 45, no. 1, pp. 69-76, 2012.

[15] H. Jiang, Z. Chen, J. Zhang, B. Wu, Y. Tian, and W. Liu, "Quasistatic test of precast reinforced concrete shear wall structure," $J$. Build. Struct., vol. 32, no. 6, pp. 34-40, 2011.

[16] J. Qian, Y. Peng, J. Zhang, H. Qin, J. Li, G. Liu, F. Zhao, and L. Li, "Tests on seismic behavior of pre-cast shear walls with vertical reinforcements spliced by grout sleeves," Build. Struct., vol. 41, no. 2, pp. 1-6, 2011.

[17] M. S. Lopes, "Experimental shear-dominated response of RC walls Part I: objectives, methodology and results", Eng. Struct., vol. 23, no. 3, pp. 229-239, 2001.

[18] H. Jiang, and X. Lv, "Experimental study on a new type of energy dissipation shear wall model under cyclic loading," World Info. Earthquake Eng., vol. 16, no. 3, pp. 63-67, 2000

(C) Sun et al.; Licensee Bentham Open.

This is an open access article licensed under the terms of the Creative Commons Attribution Non-Commercial License (http://creativecommons.org/licenses/ by-nc/3.0/) which permits unrestricted, non-commercial use, distribution and reproduction in any medium, provided the work is properly cited. 